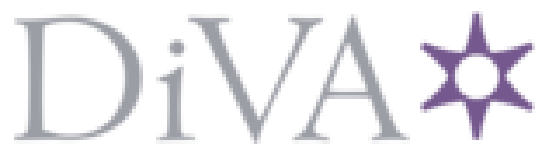

http://www.diva-portal.org

This is the published version of a paper published in Journal of Holistic Nursing.

Citation for the original published paper (version of record):

Manasatchakun, P., Choowattanapakorn, T., Roxberg, Å., Asp, M. (2018)

Community nurses' experiences regarding the meaning and promotion of healthy aging in northeastern Thailand

Journal of Holistic Nursing, 36(1): 54-67

https://doi.org/10.1177/o898010116688126

Access to the published version may require subscription.

N.B. When citing this work, cite the original published paper.

Permanent link to this version:

http://urn.kb.se/resolve?urn=urn:nbn:se:hh:diva-32726 


\section{Community Nurses' Experiences Regarding the Meaning and Promotion of Healthy Aging in Northeastern Thailand}

\author{
Pornpun Manasatchakun, MPH, PhD candidate, RNT \\ Mälardalen University \\ Boromarajonani College of Nursing Udon Thani
}

Tassana Choowattanapakorn, MSc, PhD, RNT

Chulalongkorn University

Åsa Roxberg, MSc, PhD, RNT

Linnaeus University Halmstad University

VID Specialized University

Margareta Asp, BSc, PhD, RNT

Mälardalen University

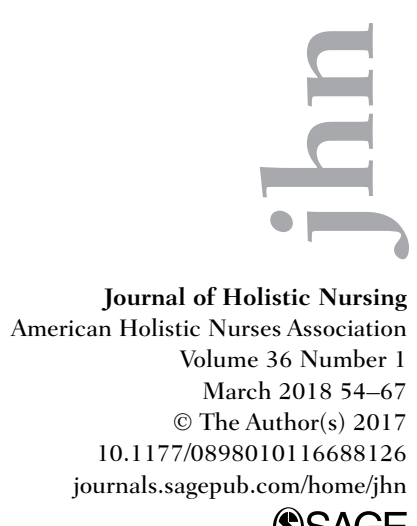

@SAGE

\begin{abstract}
Purpose: Describe community nurses' experiences regarding the meaning and promotion of healthy aging in northeastern Thailand. Method: Data were collected through five focus group interviews with 36 community nurses in northeastern Thailand. Latent content analysis was conducted to analyze the data. Findings: Healthy aging was characterized by the interconnection of older persons, older persons' family members, and the community. Healthy aging was associated with two themes: "being strong" and "being a supporter and feeling supported." The nurses' experiences in promoting healthy aging were described by the themes "providing health assessment," "sharing knowledge," and "having limited resources." Conclusions: The findings of this study provide a deeper understanding of the meaning of healthy aging from a holistic viewpoint. Community nurses must pay attention to older persons and their surroundings when planning how to promote healthy aging. Person-centeredness should be applied in practice to promote healthy aging. The current findings contribute useful information that should help policy makers develop healthy aging strategies in Thailand.
\end{abstract}

Keywords: healthy aging; health promotion; holistic care; older people; person-centeredness; qualitative research; Thai nurses

\section{Introduction}

Worldwide, interest in the concept of healthy aging is growing (Ågren, \& Berensson, 2006; World Health Organization [WHO], 2016a). As the world's aging population increases, a major concern for policy makers and health care workers is identifying how to promote health and sustain well-being among the older population (WHO, 2016a). Thailand, like other countries, has responded to this challenge by applying the concept of healthy aging through the implementation of plans for promoting health in older people (Jitapunkul \& Wivatvanit, 2008). Although healthy aging is key to promoting the well-being of older people in Thailand, the perspectives of community nurses, who have a crucial role in supporting healthy aging, in the northeastern region of the country have not been well studied. These nurses form the foundation of the nation's primary health

Authors' Note: Please address correspondence to Pornpun Manasatchakun, RN, School of Health, Care and Social Welfare, Mälardalen University, Box 325, Drottninggatan 16A, 63105 Eskilstuna, Sweden; e-mail: pornpun.manasatchakun@gmail. com. 
care system, and it is important to explore their experiences regarding the meaning and promotion of healthy aging, which may ultimately provide an avenue to increase the quality and outcome of nursing care for older individuals in northeastern Thailand.

\section{Background and Significance}

The population in Thailand is aging rapidly. Currently, the population of people aged 60 years and older (Gray, Pattaravanich, Chamchan, \& Prasartkul, 2015) in Thailand is ranked the second highest among the countries of Southeast Asia, preceded only by Singapore (Sasat \& Bowers, 2013). This population is expected to increase from 10.7 million in 2015 to over 20 million by 2035, which will include over $30 \%$ of the total population in the country (Knodel, Teerawichitchainan, Prachuabmoh, \& Pothisiri, 2015). Additionally, life expectancy is expected to increase markedly from 68.5 years in 2025 to 73.6 years in 2030 for men and from 75.0 years in 2025 to 79.1 years in 2030 for women (Sasat \& Bowers, 2013). Although older people are expected to live longer, they also face increased threats of illnesses and chronic diseases (Knodel, Teerawichitchainan, \& Pothisiri, 2016). The expansion of the aging population and increases in life expectancy require the development of appropriate policies that support older people and encourage their communities to take part in their care (Jitapunkul \& Wivatvanit, 2008). Identifying strategies that effectively promote the well-being of older people is also a challenge faced by policy makers and health care providers (Knodel et al., 2015).

Northeast Thailand is currently experiencing a demographic shift as the population ages (Knodel \& Chayovan, 2008) and remains in poverty (World Bank, 2005). Following traditional cultural norms, children take care of their parents until death (Caffrey, 1992; Knodel et al., 2016; Sasat \& Bowers, 2013); however, this can be difficult to accomplish for a poor family. Adults generally leave their children and parents to find better career opportunities or lifestyles in urban centers or overseas. For this reason, older people are often abandoned (Sudnongbua, LaGrow, \& Boddy, 2010), which can affect their health. Therefore, health promotion efforts are needed to help the aging population in northeastern Thailand live healthy lives that they can enjoy as they age.
To maintain good health within a population, primary health care providers must organize health services around people's needs in a person-centered manner to ensure that health services are effective (WHO, 2008, 2016b). Community nurses act as primary health care providers and take a prominent role in providing health care services and promoting health (Hanucharurnkul, 2007). When caring for older people, they collaborate with community health care workers to provide health support to individuals, families, and groups (Kowitt, Emmerling, Fisher, \& Tanasugarn, 2015). In this way, people in the community act as collaborators with nurses to manage their health. Thus, it is essential that community nurses maintain a holistic focus on the individuals with whom they work (WHO, 2007), as this is a fundamental aspect of person-centeredness, a prominent feature of primary health care (WHO, 2008).

Healthy aging has become a key concept in the maintenance of health and well-being in older people (Danyuthasilpe, Amnatsatsue, Tanasugarn, Kerdmongkol, \& Steckler, 2009; Thanakwang, Soonthorndhada, \& Mongkolprasoet, 2012). A global strategy of the WHO (2016a) is the maintenance of a healthy life for older people. Healthy aging has been viewed through different perspectives in Western and non-Western countries (Hansen-Kyle, 2005; Hung, Kempen, \& De Vries, 2010). From the Western perspective, healthy aging is viewed as the ability to maintain a functional body and mind with effective adaptation to the aging process and the absence of major life-threatening illness (Peel, Bartlett, \& McClure, 2004; Reed et al., 1998). In Asian countries, healthy aging is considered a state of well-being that includes happiness and good relationships with others and is free from disease and illness (Lee \& Fan, 2008; Tohit, Browning, \& Radermacher, 2012). In Thailand, healthy aging has been emphasized in the government's national policy (Jitapunkul \& Wivatvanit, 2008). Previous studies on healthy aging in Thailand have reported that healthy aging involves multiple components of well-being, including physical, mental, social, and spiritual aspects (Danyuthasilpe et al., 2009; Thanakwang et al., 2012). Healthy aging has been evaluated in a variety of ways and is influenced by a number of factors, including beliefs, the environment, socioeconomic factors, and culture (Danyuthasilpe et al., 2009; Hansen-Kyle, 2005; Peel et al., 2004). To align with 
Thailand's national plan of helping older people achieve healthy aging, community nurses focus on that goal when providing care. The implementation of such care is expected to help older people retain their health rather than merely curing and treating medical problems. This also offers the opportunity for community nurses to meet the WHO's goal of improving the health of the aging population (Robinson \& Hill, 1998).

A previous study showed that healthy aging of older people in northeast Thailand is related to the care received from health care providers (Manasatchakun, Chotiga, Roxberg, \& Asp, 2016). Even though the concept of healthy aging has been studied from different perspectives, community nurses' experiences of the meaning and promotion of healthy aging have not been assessed, especially in northeastern Thailand. Understanding the experiences of community nurses in this regard can help in the development of processes to promote healthy aging. Additionally, such understanding can help policy makers develop strategies to support both older people and health care providers in this region. Therefore, to better understand the experiences of community nurses with regard to healthy aging, the current study aimed to describe community nurses' experiences regarding the meaning and promotion of healthy aging in northeastern Thailand.

\section{Method}

\section{Study Design}

This study had an inductive descriptive design and was accomplished through focus group interviews, a qualitative research method ideally suited for exploring people's experiences, opinions, and concerns (Barbour \& Kitzinger, 1998). Focus group interviewing explores a specific set of topics and allows group members to listen and interact with one another (Barbour \& Kitzinger, 1998; Krueger \& Casey, 2014), providing useful information to researchers. Focus group interviews are therefore relevant to the aim of this study, as they were used to directly engage community nurses who work with older people in discussions about healthy aging. In this study, the participants in each group were encouraged by the moderator to share their experiences regarding the meaning and promotion of healthy aging via a group discussion.

\section{Study Setting}

This study took place in a province in the northeast region of Thailand, where more than $10 \%$ of the total population includes older people. This province consists of 20 districts with a total 25 public hospitals and 209 primary health care centers. Five districts with 5 hospitals and 31 primary health care centers were purposively selected by a public health officer as the setting for this study because they are active health care sectors and work to include activities that promote health among older people. Such activities include the provision of care services that are specific for older people and the establishment of environments that are appropriate for maintaining older people's health.

\section{Sampling}

A purposive sampling procedure was conducted to recruit participants. The inclusion criteria were as follows: (a) working as a community nurse in the full-time promotion of health services in the selected setting and (b) no limitations in Thai language communication. Thirty-six community nurses from five districts were selected by a public health officer and invited to participate by the first author (PM). The participants' backgrounds varied with regard to number of years spent caring for older persons, sex, age, and educational level. The mean age of the participants was 39 years (range: 23-52 years). Individual characteristics are shown in Table 1.

To create a setting that allowed the participants to feel comfortable during discussions, the participants were classified into five groups based on district and working environment. This led to the creation of one focus group per district. Each focus group had four to nine participants. The size chosen for the focus groups was guided by Krueger and Casey (2014).

\section{Ethical Approval and Consent to Participate}

Ethical approval was obtained from the Board Committee of the Provincial Public Health Office of the selected province in northeastern Thailand and the Regional Ethics Committee in Uppsala Sweden (Dnr 2013/019). This study followed the principles outlined in the Declaration of Helsinki (World Medical Association, 2013). All participants were 
Table 1. Overview of the Participants in Focus Group Interviews A to E $(n=5)$

\begin{tabular}{lccccc}
\hline Group (District) & Total & Sex (Female/Male) & Age (Min-Max) & $\begin{array}{c}\text { Education Level (Bachelor's } \\
\text { Degree/Master's Degree) }\end{array}$ & $\begin{array}{c}\text { Years of Experience Working } \\
\text { With Older People (Min-Max) }\end{array}$ \\
\hline A & 8 & $8 /-$ & $27-50$ & $7 / 1$ & $2-20$ \\
B & 9 & $8 / 1$ & $32-49$ & $5 / 4$ & $1-23$ \\
C & 4 & $4 /-$ & $41-51$ & $4 /-$ & $4-21$ \\
D & 8 & $8 /-$ & $23-52$ & $7 / 1$ & $1-12$ \\
E & 7 & $7 /-$ & $27-50$ & $7 /-$ & $4-13$ \\
\hline
\end{tabular}

provided with a full explanation of the study design, the purpose of the study, and the amount of time required for participation. They received both a written document and orally presented information regarding the study. They were informed that they were free to withdraw from the study at any time and were guaranteed confidentiality. All participants agreed to participate and provided signed informed consent.

\section{Data Collection}

Data were collected from March through April 2015, and group discussions were moderated by the first author (PM). A research assistant experienced with focus groups observed the participants' interactions and took field notes. She had no relationship to the participants or any influence on the interview. A pilot study with five community nurses who work outside the selected setting was utilized to test the interview guide for its appropriateness (McLafferty, 2004). The interview showed that no changes were needed. The interview guide contained open-ended questions in which the community nurses were asked to share their experiences in relation to the meaning and promoting of healthy aging. The questions included the following: "What does healthy aging mean to you?" "What characterizes healthy aging?" "Could you share your experiences in promoting healthy aging?" The participants were informed that the most important aspect of the focus group discussions was to gather different perspectives about the topic of healthy aging and that none of the answers given during the group discussions would be considered right or wrong. The amount of time allocated for the discussion of each question depended on the participants. However, if the moderator sensed that the discussion had reached saturation (Liamputtong, 2011), defined as when group members began to repeat themselves, then the group would be directed to answer the next question. Each focus group interview took approximately 60 to 90 minutes, excluding a coffee break, and was conducted in Thai. The data were audiorecorded and transcribed verbatim in Thai by the first author. The group discussions were carried out at each District Public Health Office during working hours.

The following data collection methods were used with the purpose of increasing the self-awareness of the researchers and avoiding bias (Finlay, 2002). The first author was responsible for encouraging participant discussion, motivating group members to speak, listening to the participants, and facilitating group discussions with an open mind. The first author was also responsible for making potential key points during group discussions and compiling notes after each group discussion, including a reflection on the feelings experienced by the researcher. Notably, the first author is a nursing instructor in the northeast of Thailand, which helped facilitate the discussions held with the participants working in the same region. The assistant researcher played the role of the observer and took field notes. This setup was helpful in reflecting power relations (between the moderator and the participants and/or among the participants themselves) while conducting the group discussions.

Before starting the process of data analysis, the transcriptions were read and reread by the first (PM) and second (TC) authors to ensure that rich qualitative data were generated. Although a large amount of data was received, some answers from six of the participants regarding their experiences in promoting healthy aging required further explanation. Therefore, follow-up telephone interviews were conducted by the first author in August 2015. During the follow-up, the six participants were asked to describe in detail their experiences in promoting healthy aging. They were also asked the following questions: "What do you want to do to improve your work?" and "Could you provide more detail?" The 
Table 2. Themes Based on Categories, Subcategories, and Codes Regarding the Meaning of Healthy Aging

Codes
- Living without deterioration of physical and
psychological health (not necessarily free
from disease)

- Living with a chronic diseases

- Coping with disease and dealing with feelings

- Maintaining a good temperament despite being diagnosed with a disease

- Maintaining physiological and mental functioning

- Maintaining healthy gums and teeth

- Avoiding getting sick

- Absence of chronic diseases

- Living without any signs of disease

- Absence of physiological disorders

- Holding individual authority

- Having power

- Ability to share knowledge with young people

- Teaching and guiding juniors

- Receiving appreciation

- Engaging in community activities and feeling delighted to help others

- Engaging in the Buddhist community and receiving mental support

- Maintaining relationships with people in the society

- Staying in contact with and getting help from friends

- Living with and doing things for children and feeling happy when helping and receiving support from children

- Helping children with housework and caring for grandchildren

- Sharing things with family members and accepting care from the relatives

- Giving time and showing care and kindness to other family members and feeling secure about life
- Maintaining functioning of all bodily and mental systems despite being diagnosed with chronic and/or acute disease

- Adjusting to living with a health condition or disease

- Maintaining physical and psychological well-being without the presence of a disease that would interfere with daily living

- Absence of underlying diseases

- Holding a position within the community

- Receiving respect

- Devoting oneself to others and receiving support from others in the community, such as the Buddhist community

- Leaning on other people for help and helping others in the same community such as friends

- Receiving help from and supporting children

- Providing help and receiving support from other family members, feeling a sense of being a part of family
To be involved in and receive help from the community

To be free from disease or illness

To be respected

To care for and receive assistance from relatives
Being a supporter and feeling supported follow-up interviews lasted approximately $30 \mathrm{~min}$ utes; the data collected during the interviews were audio-recorded, transcribed, and e-mailed to each participant to validate what was said to improve the reliability of the data (Polit \& Beck, 2010). All participants agreed with the data; hence, no changes were required. The data from the telephone interviews were then added to the transcriptions.

\section{Data Analysis}

The interviews and field notes were analyzed in an inductive way using latent content analysis, and no theoretical issues were included during the analysis (Graneheim \& Lundman, 2004). Data analysis was performed manually without the use of software programs. To increase the rigor of the 
Table 3. Themes Based on Categories, Subcategories, and Codes Regarding the Promotion of Healthy Aging

\section{Cales}

- Trying to gather clients' information

- Asking what clients are feeling

- Obtaining clients' background information

- Focusing on screening for individual health problems

- Performing health examinations

- Determining health risks

- Detection of factors that influence disease and/or health conditions

- Attempting to talk to and listen to clients

- Home visits to create a closer relationship with the client

- Asking about a client's concerns

- To be aware of own position

- To allow older people to do what they want to do

- To encourage groups of older people to work together

- To offer support persons and group discussions

- Focusing on tacit knowledge

- Folk wisdom of older people

- Integrating knowledge assets

- Searching for a partner

- The importance of an older person's family members

- Municipal support for programs to promote healthy aging

- Monks having a key role in leading activities

- Financial support for the care of older persons was withdrawn from the organization and had to be supplemented by other organizations

- Financial support from the alliance network was intermittent

- Many organizations had to cooperate to secure funding

- The absence of additional nurses limited engagement in proactive activities and reduced the care of the older population

- The staff became discouraged

- Work duties were reliant on work indicators, which added responsibilities apart from caring for the aged population

- The staff had a higher workload compared with other authorities
- To identify general information

- To evaluate physical and mental health

- To investigate factors affecting health

- To focus on older persons' needs

- Focusing on group supportive

- To apply local wisdom and culture

- To emphasize the importance of the stakeholder

- Having the ability to access good resources

- Lack of power to procure financial support

- Discontinuous budget constraints

- Only one nurse in the organization

- Workloads, excluding aged care, depended on work indicators
Initial self-help groups

Networking

Lack of financial support

\section{Having limited resources}

research and reduce element bias, the first and second authors (PM and TC) independently analyzed the data. The transcribed data were read several times by the authors (PM and TC) to obtain a comprehensive sense of the meaning as a whole (Graneheim \& Lundman, 2004). The authors (PM and TC) identified meaning units belonging to the content areas of the meaning of healthy aging and the promotion of healthy aging, and each content area was then condensed. Each 
condensed meaning unit was then labeled with a code, and the authors (PM and TC) compared the differences and similarities of the codes. Similar codes were placed into unique subcategories and categories. Next, themes were arranged according to the underlying meanings of the categories. In this process, field notes describing nonverbal communication were used to interpret the underlying meanings of the categories and to identify emerging themes. Following this, the interpretations were verified. The authors (PM and TC) discussed the emerged findings throughout the data analysis process. Any differences in viewpoints were discussed and clarified by the two authors (PM and TC) to ensure that a consensus was reached. The analysis process was performed by both authors (PM and TC) in Thai to reduce any potential barriers involving language (Squires, 2008). Next, all transcripts were translated into English by a professional translator to ensure their accuracy (Regmi, Naidoo, \& Pilkington, 2010). All authors had access to the data to validate the analysis process used. To prevent bias during the analysis, all authors rechecked the entire process of analysis. All authors discussed the final findings that were reported in English and attempted to avoid prejudgments. The final findings were agreed on by all authors. Table 2 and Table 3 provide an example of the process of data analysis.

\section{Results}

The meaning of healthy aging consisted two themes: being strong and being a supporter and feeling supported. Experiences with the promotion of healthy aging centered on three themes: providing health assessments, sharing knowledge, and having limited resources.

\section{The Meaning of Healthy Aging}

Theme: Being Strong. Healthy aging was defined as being strong. Being strong was characterized by an individual's ability to maintain physical and mental functions. The community nurses broadly assessed the indicators of healthy aging as physical appearance, the ability to perform routine activities in daily life, and the potential to prevent functional decline. Healthy aging was considered achievable despite the presence of disease, as long as the complications associated with a disease could be controlled.
However, some of the nurses viewed healthy aging as the absence of disease and mental illness. The concept of healthy aging included emotional wellbeing related to the ability to perform daily living activities and self-care as well as the ability to make decisions. Being strong was defined as maintaining not only bodily and mental functions but also the power to influence others, including authority figures, which was experienced as receiving respect from others. Overall, this theme consisted of three categories: (a) to be able to control complications associated with disease, (b) to be free from disease or illness, and (c) to be respected.

To be able to control complications associated with disease. Healthy aging was defined as the ability to control complications associated with diseases that afflict older persons; that is, despite having been diagnosed with a disease, an older individual could make adjustments to live with the diagnosis and to continue performing daily living activities.

Even if an older person has high blood pressure and diabetes, they can be considered healthy as long as they take medicine regularly, see their doctor and have no complications. (Focus Group A, Participant 1)

Healthy aging was associated with the ability to control a disease to avoid further complications.

To be free from disease or illness. Healthy aging was defined as an absence of disease, including infectious diseases and chronic diseases, such as heart disease, hypertension, cancer, and mental health disorders. Such diseases were considered detrimental to the performance of daily self-care activities by older persons.

For me, they should not have any diseases. They must be totally healthy, both physically and psychologically. If they have a disease, we cannot consider them healthy. They should still have their own natural 20 teeth and no difficulties with eating, chewing, or swallowing. (Focus Group D, Participant 1)

The community nurses explained that diseases that threatened older people's lives and routines influenced their physical function and ability to perform daily activities.

To be respected. Receiving respect from others, including being able to hold an important position as 
a powerful person in the community, was part of the meaning of healthy aging. Receiving respect also included the ability to share wisdom and guide youngsters, to receive appreciation for what one achieved, and to maintain relationships with others.

The aged should be admired by the community and the young generation. For example, in a village, a senior citizen should act as a judge when there is a conflict. (Focus Group E, Participant 5)

Earning respect from others and having a sense of authority enabled older individuals to feel important, valued, and healthy.

Theme: Being a Supporter and Feeling Supported. Healthy aging was also defined as being a supporter and feeling supported, that is, providing assistance to and receiving help from others. This included both socioeconomic and emotional support, as well as social assistance. Such support was related to positive emotions, such as feelings of comfort and happiness. Overall, this theme consisted of two categories: (a) to be involved in and receive help from the community and (b) to care for and receive assistance from relatives.

To be involved in and receive help from the community. The definition of healthy aging included the maintenance of interactions with other older people and society at large. These interactions allowed older individuals to feel like they were part of the community, such as through engaging in activities and societies (including older persons' groups), supporting others in the community and performing charity work. Maintaining interactions with others also encompassed being generous and helpful toward others in the community. Simultaneously, this theme was defined as receiving support from the community, including spiritual and mental support to improve one's sense of contentment.

They should attend activities in the community and not live alone. They must work for the community and socialize within it. They should have a role in the community. I think that one is healthy as long as they can support their society. They support their neighbors. When one falls ill, the others go to visit and help him/her. (Focus Group C, Participant 3)

Further discussion included engagement in Buddhist practices, experiencing happiness in life, and gaining knowledge regarding the Buddha's teachings.

They should attend community-like rituals at the temple. This is happiness. They should engage in Buddhist practices that help them learn the Buddha's teachings and the principal of Dharma from monks. For example, if one does good things, he/she will receive good things in return. (Focus Group D, Participant 3)

Healthy aging was associated with having a role in society, working for the community, and supporting others in the community. It involved providing something to the community and receiving something in return.

To care for and receive assistance from relatives. The definition of healthy aging included caring for relatives as well as receiving assistance from relatives, which was related to feeling positive emotions.

I know an older person who lives with her nephew, who is studying in a primary school close to the house. The nephew's parents work in other provinces, and the grandma helps take care of the child. She receives an income from her children, who transfer money to her account. To ensure she has food to eat, her children who live in the same village deliver food to her. (Focus Group B, Participant 3)

Taking care of descendants and receiving assistance from relatives, including economic and material support to facilitate daily living activities, were components identified as important to healthy aging.

\section{The Promotion of Healthy Aging}

Theme: Providing Health Assessments. Providing health assessments was depicted as a routine part of the work performed by community nurses. Such health assessments involved evaluations of health status, including the collection of physical and psychological data, with the goal of identifying the needs of each older person by identifying the health determinants contributing to their healthy aging. Two categories emerged from this theme: to perform health screenings and to assess key factors.

To perform health screenings. The community nurses considered the screening of older persons' health as part of the promotion of healthy aging. The 
purpose of such screening was to determine the status of a person's physical and mental functions. The focus of this category was on the proactive work of the community nurses in using their skills to assess individual health problems, such as chronic diseases and/or acute illnesses, in each older person.

I have performed health examinations. We cooperated with the sub-district's administrative organization. We went to each community to screen each person for diseases, which helped us make an initial determination. (Focus Group D, Participant 2)

The community nurses described health screening as a way to prevent suffering and the effects of disease complications.

To assess key factors. This category described the ability to assess the key factors that affect older people's health as a key part of promoting healthy aging. The purpose was to focus on the context of each person's concerns and to determine how these influenced the person's health.

To identify their levels of wellness helps us determine how to support them. We should know their standards. They are different. They should be considered as subsets because each person thinks differently in his/her own way. (Focus Group B, Participant 6)

Home visits were an option to assess an individual's needs. Moreover, listening to and talking with each older person was a key component in identifying and understanding the factors associated with a problem.

I meet my clients one by one. I investigate what they want. We have a chance to talk to our clients. I visit each older person in his or her residence. Some just need to talk about their health. They need someone to talk with to heal their souls. (Focus Group A, Participant 3)

The promotion of healthy aging was defined as an exploration of what an older person needs regarding his or her health. This could be characterized as seeking to understand an older person's behaviors and the determinants of his or her health.

Theme: Sharing Knowledge. The community nurses focused on the values and wisdom of older persons when promoting healthy aging. The nurses listened to the older persons and to others who influenced their lives. They learned the ways in which the older persons shared what they did to take care of their health. This included having a chance to discuss what the older persons thought and what they learned from each other. Furthermore, this included a belief in the abilities of the people in the community to create mutual support for each other. This theme comprised two categories: (a) initial self-help groups and (b) networking.

Initial self-help groups. This category included the use of self-help groups, defined as a group of older persons who supported each other, for promoting healthy aging. The community nurses viewed themselves as supporters who authorized the older persons to perform activities and share the results with each other. The purpose of this process was to help others identify solutions to achieve success and engage in sustainable work while promoting healthy aging.

We do not need to suggest or train them, just listen to them. "Phaya," which is passed down from ancestors, can be used to apply health services to harmonize with the local context. The senior citizens have meetings to share what they do to stay healthy. We have an older person who is a health idol for the aged in other villages. We should support what older persons do. (Focus Group B, Participant 4)

The community nurses paid attention to what the older persons in their care said. They listened to them. They supported what the older persons felt the need to do and tried to understand them. The community nurses also used folk wisdom and traditions to help promote healthy aging in the community. They supported older people's experiences, abilities, and skills, which emphasized autonomy.

Networking. The community nurses worked with the assistance of older persons' families and other stakeholders to create a network that was supportive for promoting healthy aging. The nurses and their networks shared information and learned about the health of the target group through their activities with the older persons.

We see our target group there and learn about the health of our parties. For example, when we have a party, we see that they eat fatty and salty food. We 
learn what type of food they eat. When we eat together, public health volunteers can suggest ways to eat good food. (Focus Group D, Participant 4)

The community nurses referred to public health volunteers as supporters linked to clinical care and as good resources for helping the nurses promote healthy aging.

When asked to explain the activities that they collaborated with the network on, they gave examples and relayed their experiences with another stakeholder who worked with a monk in the community:

Our current activity is "Moo Baan Sin Ha" (The Five Precept Village), which is held every Friday. It is led by Master X, the admirable monk. We have a model village that is selected by the public health volunteers. (Focus Group B, Participant 1)

The community nurses collaborated with people in the communities who were able to actively participate in work and involved them in activities. These activities were not led by the nurses; rather, the nurses empowered the people in the communities to lead their own activities. The key people the nurses involved included a monk and another individual who was considered a good role model for others in the community.

Theme: Having Limited Resources. This theme reflected a weakness that affected the nurses' work. The community nurses mentioned limitations when they created new projects for improving healthy aging. This theme was described by two categories: (a) lack of financial support and (b) insufficient workforce.

Lack of financial support. This category focused on the external factors that influenced the work of the nurses in the community. The community nurses stated that they had to follow policies and that they inevitably confronted problems such as a lack of materials.

It's hard to encourage other authorities to support our work. We must think about what to say to encourage them to fund us. Understanding how to maintain a project is also a burden in our work. (Focus Group E, Participant 3)

The community nurses were concerned about budgets and financial support, an important factor when promoting healthy aging.
Insufficient workforce. The community nurses explained that there was a shortage in the present number of staff. This affected their work and increased their workloads. They mentioned that having to relay key performance indicators was one of the factors that affected their work.

We have only a few staff. I have to fill in the data on many documents. We have to show the outcome figures. It's difficult to deal with everything. (Focus Group E, Participant 2)

Some of the community nurses were concerned about their work situations influencing their interactions with older persons.

The work is so demanding. I have no time to ask questions of and talk to older people. I want to work in caring for older persons only. I don't want to be loaded with other jobs. (Focus Group A, Participant 2)

The community nurses spent most of their time following procedures. The work was organized in a way that limited the possibilities for the community nurses to listen to and care for older persons.

\section{Discussion}

The present study is the first to report on community nurses' experiences regarding the meaning and promotion of healthy aging in northeastern Thailand. Healthy aging was defined as consisting of multidimensional components of health and was considered representative of the interconnection of physiological, psychological, social, and spiritual aspects. This can be explained as the foundation of holistic health, which views health as being a whole (Berg \& Sarvimäki, 2003; Herberts \& Eriksson, 1995; Payne, 1983).

Healthy aging can be described based on the classic definition of health made by the WHO (2016c). The scope of healthy aging shares similarity with the professional viewpoint (Hansen-Kyle, 2005; Hung et al., 2010) that healthy aging consists of physical, mental, and social domains of health. The present findings are in line with previous studies reporting that healthy aging includes the absence of major lifethreatening complications as well as the maintenance of physical and mental functioning (Peel et al., 2004). In addition, healthy aging involves an individual's maintenance of autonomy, such as the ability to take care of oneself. This is consistent with the definition of healthy aging viewed from a sociological perspec- 
tive (Hansen-Kyle, 2005). However, the findings in the current study added the domain of spiritual health to the meaning of healthy aging. The spiritual aspect of health can be understood based on older persons' practices of religious teachings. The community nurses described healthy aging as being a supporter and feeling supported, which are associated with helping others and being generous. This finding is consistent with a previous study that showed that practicing Buddhism is linked to healthy aging (Thiamwong, McManus, \& Suwanno, 2013). Healthy aging was further defined as connectedness with other older persons and their surroundings. This relates to the interaction between individual behaviors and social environments, especially the community where older people live. This study showed that healthy aging is associated with receiving social support and respect from others, which is consistent with previous findings showing that healthy aging is influenced by staying connected with family members and receiving support from others (Danyuthasilpe et al., 2009; Thanakwang et al., 2012). This may also refer to the traditional Thai value that people in society should show respect to older persons (Caffrey, 1992; Thanakwang \& Soonthorndhada, 2011). Moreover, this finding may be linked to a doctrine of Buddhism that emphasizes the importance of the moral obligation that children should support their parents (Thanakwang \& Soonthorndhada, 2011).

Concerning the promotion of healthy aging, the community nurses focused on older persons living within communities. The present findings are consistent with the principle of person-centered care (McCormack, Karlsson, Dewing, \& Lerdal, 2010; McCormack \& McCance, 2006), especially the notion of person-centered processes (McCormack, Karlsson, et al., 2010), which focus on client's individual beliefs and values when performing care. It also indicates the need for engagement, having a sympathetic presence, shared decision making, and the provision of holistic care (McCormack, Dewing, et al., 2010; Morgan \& Yoder, 2012; Robinson \& Hill, 1998). Holistic care emphasizes the value of individuals as whole persons and focuses on the interdependence of their parts (Morgan \& Yoder, 2012). According to the findings in the current study, health assessments were the main avenue used by the community nurses to promote healthy aging. This reflects the background of fundamental nursing knowledge used for health promotion based on preassessment tools (Robinson \& Hill, 1998). The community nurses also highlighted the values and wisdom of older persons. They emphasized that older persons should be responsible for their own behaviors. They tried to listen to older persons and others who had influence on the older persons' lives. This finding also shows that community nurses are concerned of the older person's needs. This can be linked to the importance placed on treating older persons with dignity (McCormack, Karlsson, et al., 2010) and being respectful as a fundamental component of person-centered care (Morgan \& Yoder, 2012). Listening is an occupational requirement for community nurses. Community nurses should consider an older person's situation and how information is being conveyed by this person without judging them. This may be helpful for increasing understanding of older persons' insiderness (Todres, Galvin, \& Dahlberg, 2014). This is also the key to empowerment, which helps encourage autonomy and enhances self-confidence (Morgan \& Yoder, 2012). Moreover, it can help others understand the feelings of older people, which is the foundation of humanized care (Todres et al., 2014).

The theme of sharing knowledge represents the fact that community nurses attempt to use a holistic approach when promoting healthy aging. Because humans do not thrive when living completely alone, they must connect with others (Berg \& Sarvimäki, 2003). This finding is in line with a previous study (Berg, Hedelin, \& Sarvimäki, 2005) reporting that health promotion is linked to holistic nursing. Holistic approaches, therefore, influence health promotion activity (Morgan \& Marsh, 1998), which is consistent with a previous study of district nurses in Sweden (Strandberg, Ovhed, Borgquist, \& Wilhelmsson, 2007). The community nurses considered the interactions that existed between older persons and their surroundings. This included the relationships that formed between the community nurses and the older persons. They focused on the friends and family members of the older person as a fundamental resource for health promotion (Epp, 1987). Village health volunteers and Buddhist monks were viewed as a major source of support to the community nurses in their work promoting healthy aging. These findings are consistent with previous studies that health volunteers and monks play an important role in supporting the health of people in the community (Kowitt et al., 2015; Sasiwongsaroj, Pornsiripongse, Burasith, Ketchamnong, \& Kusakulrat, 2012). This can be linked to the effects of religion on emotional and spiritual health among older persons (Kuhirunyaratn, Pongpanich, Somrongthong, Love, \& Chapman, 2007). 
Having limited resources was the last theme that emerged when the community nurses discussed their experiences in promoting healthy aging. This theme is representative of the fact that increasing workload and lack of staff had significant impact on the nurses' work, which results in a lack of time to provide necessary information to older persons and to receive information from them. This can detrimentally affect the nurses' work. As previously described, community nurses use a holistic approach and show concern about older persons living in the community when promoting healthy aging. Personcenteredness is considered to emphasize a holistic approach (McCormack, Karlsson, et al., 2010), taking into account older persons as a whole and focusing not only on their health conditions but also on their abilities to care for themselves in daily life, their support networks of family members, and their community backgrounds. It was found that community nurses listened to older persons and were also concerned with these individuals' needs. However, they were influenced by the limited resources available to them, which may reduce their opportunities to achieve their goal of practicing person-centeredness for the promotion of healthy aging. Consequently, these limitations may create an obstacle in working with older people and their surroundings. This finding is similar to a report by Kemppainen, Tossavainen, and Turunen (2013). Notably, these barriers may affect the care environment (McCormack, Karlsson, et al., 2010) and reduce the ability to engage in person-centered care to promote healthy aging. The community nurses provided key insights regarding the implementation of healthy aging strategies. Therefore, the findings of this study can be useful for policy makers to evaluate appropriate practices and concerns from a bottom-up perspective.

\section{Methodological Considerations}

In the current study, trustworthiness was considered in terms of credibility, dependability, and transferability (Graneheim \& Lundman, 2004; Polit \& Beck, 2010). To ensure the credibility of this study, each part of the study was described in detail. The participants who were chosen had various backgrounds, with differences in level of experience in providing care, age, and education, to provide a variety of data sources. However, only one man participated in this study. This can potentially be considered a limitation because the data might not fully represent the male perspective.
Another concern is that the participants in each group had various working experiences and held different hierarchical positions, which could have influenced the focus groups interviews. Two authors performed the analysis to increase the comprehensiveness of the findings. All of the data were checked and discussed during data analysis by all the researchers in order to ensure credibility. To ensure dependability, the authors described the research design and evaluated the effectiveness of the analysis processes used. There was no specific theory or conceptual framework underlying the research design, meaning that no specific theory was used when analyzing and interpreting the data. The authors utilized an inductive approach instead of a deductive approach to derive categories and themes from the raw data. Transferability from this study is limited because the study was conducted in a single region in Thailand. However, the findings of this study may be transferable to similar contexts, such as other provinces in the northeast region of Thailand.

\section{Conclusions}

In this study, healthy aging was defined as "being strong" and "being a supporter and feeling supported." These definitions emphasize the interconnection of the mental, physical, social, and spiritual aspects of healthy aging. The nurses' experiences regarding the promotion of healthy aging consisted of "providing health assessment," "sharing knowledge," and "having limited resources." Community nurses link their experiences in promoting healthy aging to the stakeholders they interact with and to their work situations. They perform health assessments and focus on sharing knowledge between older persons and their communities. However, limited access to resources was defined as a major barrier for the promotion of healthy aging and regarding adherence to the concepts of person-centered care (McCormack, Dewing, et al., 2010). These findings provide insight into the viewpoints of healthy aging held by community nurses in northeastern Thailand. Policy makers should consider these viewpoints when developing and improving strategies that promote healthy aging in this region.

\section{References}

Ågren, G., \& Berensson, K. (2006). Healthy ageing: A challenge for Europe. Stockholm, Sweden: Huksvarna/Swedish National Institute of Public Health.

Barbour, R., \& Kitzinger, J. (1998). Developing focus group research: Politics, theory and practice. London, England: Sage. 
Berg, G. V., Hedelin, B., \& Sarvimäki, A. (2005). A holistic approach to the promotion of older hospital patients' health. International Nursing Review, 52, 73-80. doi: $10.1111 / \mathrm{j} .1466-7657.2004 .00264 . x$

Berg, G. V., \& Sarvimäki, A. (2003). A holistic-existential approach to health promotion. Scandinavian Journal of Caring Sciences, 17, 384-391. doi:10.1046/j.0283-9318. 2003.00240.x

Caffrey, R. A. (1992). Caregiving to the elderly in northeast Thailand. Journal of Cross-Cultural Gerontology, 7, 117 134. doi:10.1007/BF00115940

Danyuthasilpe, C., Amnatsatsue, K., Tanasugarn, C., Kerdmongkol, P., \& Steckler, A. B. (2009). Ways of healthy aging: A case study of elderly people in a northern Thai village. Health Promotion International, 24, 394403. doi: 10.1093/heapro/dap038

Epp, J. (1987). Achieving health for all: A framework for health promotion. Ottawa, Ontario, Canada: Ministry of Supply and Services.

Finlay, L. (2002). "Outing" the researcher: The provenance, process, and practice of reflexivity. Qualitative Health Research, 12,531-545. doi:10.1177/104973202129120052

Graneheim, U. H., \& Lundman, B. (2004). Qualitative content analysis in nursing research: Concepts, procedures and measures to achieve trustworthiness. Nurse Education Today, 24, 105-112. doi:10.1016/j.nedt.2003.10.001

Gray, R. S., Pattaravanich, U., Chamchan, C., \& Prasartkul, P. (2015). Perceived negative and positive impacts of redefining older persons in Thailand. Journal of Population and Social Studies, 23, 1-14.

Hansen-Kyle, L. (2005). A concept analysis of healthy aging. Nursing Forum, 40, 45-57. doi: 10.111 1/j.1744-6198.2005. 00009.x

Hanucharurnkul, S. (2007). Nurses in primary care and the nurse practitioner role in Thailand. Contemporary Nurse, 26, 83-93. doi:10.5555/conu.2007.26.1.83

Herberts, S., \& Eriksson, K. (1995). Nursing leaders' and nurses' view of health. Journal of Advanced Nursing, 22, 868-878.

Hung, L., Kempen, G. I. J. M., \& De Vries, N. K. (2010). Cross-cultural comparison between academic and lay views of healthy ageing: A literature review. Ageing $\mathcal{E}$ Society, 30, 1373-1391. doi:10.1017/S0144686X100 00589

Jitapunkul, S., \& Wivatvanit, S. (2008). National policies and programs for the aging population in Thailand. Ageing International, 33, 62-74. doi:10.1007/s12126009-9027-6

Kemppainen, V., Tossavainen, K., \& Turunen, H. (2013). Nurses' roles in health promotion practice: An integrative review. Health Promotion International, 28, 490-501. doi:10.1093/heapro/das034

Knodel, J., \& Chayovan, N. (2008). Population aging and the well-being of older persons in Thailand (Report No. 08659). Ann Arbor: Institute for Social Research, University of Michigan.
Knodel, J., Teerawichitchainan, B. P., \& Pothisiri, W. (2016). Caring for Thai older persons with long-term care needs (Research Report No. 16-854). Ann Arbor: Institute for Social Research, University of Michigan. Retrieved from http://ink.library.smu.edu.sg/cgi/viewcontent.cgi?article= 3202\&context=soss_research

Knodel, J., Teerawichitchainan, B. P., Prachuabmoh, V., \& Pothisiri, W. (2015). The situation of Thailand's older population: An update based on the 2014 survey of older persons in Thailand (Research Report No. 15-847). Ann Arbor: University of Michigan, Institute for Social Research. Retrieved from http://www.psc.isr.umich.edu/pubs/pdf/rr15-847.pdf

Kowitt, S. D., Emmerling, D., Fisher, E. B., \& Tanasugarn, C. (2015). Community health workers as agents of health promotion: Analyzing Thailand's village health volunteer program. Journal of Community Health, 40, 780-788. doi:10.1007/s 10900-015-9999-y

Krueger, R. A., \& Casey, M. A. (2014), Focus groups: A practical guide for applied research (5th ed.). Thousand Oaks, CA: Sage.

Kuhirunyaratn, P., Pongpanich, S., Somrongthong, R., Love, E. J., \& Chapman, R. S. (2007). Social support among elderly in Khon Kean Province, Thailand. Southeast Asian Journal of Tropical Medicine and Public Health, 38, 936-946.

Lee, L. Y. K., \& Fan, R. Y. K. (2008). An exploratory study on the perceptions of healthy ageing among Chinese adults in Hong Kong. Journal of Clinical Nursing, 17, 13921394. doi:10.1111/j.1365-2702.2007.02273.x

Liamputtong, P. (2011). Focus group methodology: Principle and practice. London, England: Sage. doi:10.4135/97814 73957657

Manasatchakun, P., Chotiga, P., Roxberg, Å., \& Asp, M. (2016). Healthy ageing in Isan-Thai culture -A phenomenographic study based on older persons' lived experiences. International Journal of Qualitative studies on Health and Well-being, 11, 1-9. doi: 10.3402/qhw.v11.29463

McCormack, B., Dewing, J., Breslin, L., Coyne-Nevin, A., Kennedy, K., Manning, M., .. . Slater, P. (2010). Developing person-centered practice: Nursing outcomes arising from changes to the care environment in residential settings for older people. International Journal of Older People Nursing, 5, 93-107. doi:10.1111/j.1748-3743.2010.00216.x

McCormack, B., Karlsson, B., Dewing, J., \& Lerdal, A. (2010). Exploring person-centredness: A qualitativemeta-synthesis of four studies. Scandinavian Journal of Caring Sciences, 24, 620-634. doi:10.1111/j.1471-6712.2010.00814.x

McCormack, B., \& McCance, T. V. (2006). Development of a framework for person-centered nursing. Journal of Advanced Nursing, 56, 472-479. doi:10.1111/j.1365-2648. 2006.04042.x

McLafferty, I. (2004). Focus group interviews as a data collecting strategy. Journal of Advanced Nursing, 48, 187194. doi:10.1111/j.1365-2648.2004.03186.x

Morgan, I. S., \& Marsh, G. W. (1998). Historic and future health promotion contexts for nursing. Image, 30, 379383. doi:10.1111/j.1547-5069.1998.tb01337.x 
Morgan, S., \& Yoder, L. H. (2012). A concept analysis of person-centered care. Journal of Holistic Nursing, 30, 615. doi: 10.1177/0898010111412189

Payne, L. (1983). Health: A basic concept in nursing theory. Journal of Advanced Nursing, 8, 393-395. doi:10.1111/ j.1365-2648.1983.tb00462.x

Peel, N., Bartlett, H., \& McClure, R. (2004). Healthy ageing: How is it defined and measured? Australasian Journal on Ageing, 23, 115-119. doi:10.1111/j.1741-6612.2004. 00035.x

Polit, D. F., \& Beck, C. T. (2010). Essentials of nursing research: Appraising evidence for nursing practice ( 7 th ed.). Philadelphia, PA: Wolters Kluwer Health/Lippincott Williams \& Wilkins.

Reed, D. M., Foley, D. J., White, L. R., Heimovitz, H., Burchfiel, C. M., \& Masaki, K. (1998). Predictors of healthy aging in men with high life expectancies. American Journal of Public Health, 88, 1463-1468. doi:10.2105/ AJPH.88.10.1463

Regmi, K., Naidoo, J., \& Pilkington, P. (2010). Understanding the processes of translation and transliteration in qualitative research. International Journal of Qualitative Methods, 9, 16-26.

Robinson, S., \& Hill, Y. (1998). The health promoting nurse. Journal of Clinical Nursing, 7, 232-238. doi:10.1046/ j. 1365-2702.1998.00151.x

Sasat, S., \& Bowers, B. J. (2013). Spotlight Thailand. The Gerontologist, 53, 711-717. doi:10.1093/geront/gnt038

Sasiwongsaroj, K., Pornsiripongse, S., Burasith, Y., Ketchamnong, P., \& Kusakulrat, N. (2012). Buddhist temple: The well-being space for the aged in Thailand. Journal of Population and Social Studies, 20, 2-19.

Squires, A. (2008). Language barriers and qualitative nursing research: Methodological considerations. International Nursing Review, 55, 265-273. doi:10.1111/j.1466-7657. 2008.00652.x

Strandberg, E. L., Ovhed, I., Borgquist, L., \& Wilhelmsson, S. (2007). The perceived meaning of a (w)holistic view among general practitioners and district nurses in Swedish primary care: A qualitative study. BMC Family Practice, 8 , 8. doi:10.1186/1471-2296-8-8

Sudnongbua, S., LaGrow, S., \& Boddy, J. (2010). Feelings of abandonment and quality of life among older persons in rural northeast Thailand. Journal of Cross-Cultural Gerontology, 25, 257-269. doi:10.1007/s10823-010-9126-6

Thanakwang, K., \& Soonthorndhada, K. (2011). Mechanisms by which social support networks influence healthy aging among Thai community-dwelling elderly. Journal of Aging and Health, 23, 1352-1378. doi:10.1177/08982643114 18503

Thanakwang, K., Soonthorndhada, K., \& Mongkolprasoet, J. (2012). Perspectives on healthy aging among Thai elderly: A qualitative study. Nursing \& Health Sciences, 14, 472479. doi:10.1111/j.1442-2018.2012.00718.x

Thiamwong, L., McManus, M. S., \& Suwanno, J. (2013). Development of the Thai healthy aging model: A grounded theory study. Nursing \& Health Sciences, 15, 256-261. doi: $10.1111 /$ nhs. 12028

Todres, L., Galvin, K. T., \& Dahlberg, K. (2014). "Caring for insiderness": Phenomenologically informed insights that can guide practice. International Journal of Qualitative Studies on Health and Well-Being, 9, 21421. doi:10.3402/ qhw.v9.21421

Tohit, N., Browning, C. J., \& Radermacher, H. (2012). "We want a peaceful life here and hereafter": Healthy ageing perspectives of older Malays in Malaysia. Ageing $\&$ Society, 32, 405-424. doi:10.1017/S0144686X11000316

World Bank. (2005). Thailand-Northeast economic development report. Washington, DC: Author.

World Health Organization. (2007). People-centered health care: A policy framework. Manila, Philippines: WHO Regional Office for the Western Pacific.

World Health Organization. (2008). Primary care: Putting people first. Retrieved from http://www.who.int/whr/2008/ 08_chap3_en.pdf?ua $=1$

World Health Organization. (2016a). Multisectoral action for a life course approach to healthy ageing: Draft global strategy and plan of action on ageing and health. Retrieved from http://apps.who.int/gb/ebwha/pdf_files/WHA69/A69_17-en. pdf?ua $=1$

World Health Organization. (2016b). Primary health care. Retrieved from http://www.who.int/topics/primary_health_ care/en/

World Health Organization. (2016c). WHO definition of health. Retrieved from http://www.who.int/about/definition/en/print.html

World Medical Association. (2013). World MedicalAssociation declaration of Helsinki: Ethical principles for medical research involving human subjects. Retrieved from http:// www.wma.net/en/30publications/10policies/b3/index. html.pdf?print-media-type $\&$ footer-right $=\% 5$ bpage $\% 5 \mathrm{~d}$ $1 \% 5$ bto

Pornpun Manasatchakun is a PhD candidate at the School of Health, Care and Social Welfare, Mälardalen University, Sweden, and a lecturer at the Boromarajonani College of Nursing Udon Thani, Thailand.

Tassana Choowattanapakorn is a senior lecturer and an assistant professor at Faculty of Nursing, Chulalongkorn University, Bangkok, Thailand.

Åsa Roxberg is a senior lecturer and an associate professor at School of Health and Caring Sciences, Linnaeus University, Växjö, Sweden, the School of Health and Welfare, Halmstad University, Halmstad, Sweden, and VID Specialized University, Bergen, Norway, respectively.

Margareta Asp is a senior lecturer and an associate professor at the School of Health, Care and Social Welfare, Mälardalen University, Eskilstuna-Västerås, Sweden. 